\title{
Response shift, recall bias and their effect on measuring change in health-related quality of life amongst older hospital patients
}

\author{
Steven McPhail ${ }^{* 1,2,3}$ and Terry Haines $3,4,5$
}

\begin{abstract}
Background: Assessments of change in subjective patient reported outcomes such as health-related quality of life (HRQoL) are a key component of many clinical and research evaluations. However, conventional longitudinal evaluation of change may not agree with patient perceived change if patients' understanding of the subjective construct under evaluation changes over time (response shift) or if patients' have inaccurate recollection (recall bias). This study examined whether older adults' perception of change is in agreement with conventional longitudinal evaluation of change in their HRQoL over the duration of their hospital stay. It also investigated this level of agreement after adjusting patient perceived change for recall bias that patients may have experienced.

Methods: A prospective longitudinal cohort design nested within a larger randomised controlled trial was implemented. 103 hospitalised older adults participated in this investigation at a tertiary hospital facility. The EQ-5D utility and Visual Analogue Scale (VAS) scores were used to evaluate HRQoL. Participants completed EQ-5D reports as soon as they were medically stable (within three days of admission) then again immediately prior to discharge. Three methods of change score calculation were used (conventional change, patient perceived change and patient perceived change adjusted for recall bias). Agreement was primarily investigated using intraclass correlation coefficients (ICC) and limits of agreement.
\end{abstract}

Results: Overall 101 (98\%) participants completed both admission and discharge assessments. The mean (SD) age was 73.3 (11.2). The median (IQR) length of stay was 38 (20-60) days. For agreement between conventional longitudinal change and patient perceived change: ICCs were 0.34 and 0.40 for EQ-5D utility and VAS respectively. For agreement between conventional longitudinal change and patient perceived change adjusted for recall bias: ICCs were 0.98 and 0.90 respectively. Discrepancy between conventional longitudinal change and patient perceived change was considered clinically meaningful for 84 (83.2\%) of participants, after adjusting for recall bias this reduced to 8 (7.9\%).

Conclusions: Agreement between conventional change and patient perceived change was not strong. A large proportion of this disagreement could be attributed to recall bias. To overcome the invalidating effect of response shift (on conventional change) and recall bias (on patient perceived change) a method of adjusting patient perceived change for recall bias has been described.

\section{Background}

Measurement of change in patient outcomes is important when evaluating the effect of health interventions or disease processes on an individual or group[1]. Objective tests of patient body, structure or function can be simple (e.g. blood pressure) or complex (e.g. positron emission

*Correspondence: steven_mcphail@health.qld.gov.au

${ }^{1}$ Centre for Functioning, Disability and Health Research, Queensland Health, Buranda Plaza, Corner of Ipswich Road and Cornwall Street, Brisbane, Australia Full list of author information is available at the end of the article tomography). These are widely used, and can provide insights essential for ongoing patient management. However, not all health constructs of importance can be measured using objective measures such as these[2]. Constructs such as pain, fatigue, depression and ultimately health-related quality of life can be just as important (if not more so) for evaluating treatment effect in some conditions. However, these constructs generally need to be measured using more subjective 
approaches[2,3]. Increasingly, funding decisions in health care are being based upon whether particular health programs or diseases impact upon subjectively measured outcomes such as these[2-4].

A conventional approach to evaluation of change in self-reported outcomes involves completion of a standardised measurement instrument at a certain time point (e.g. pre-treatment) and then again at a later time point (e.g. post treatment)[3,5]. Conventional measurement of change in the self-reported outcome involves subtracting the pre-treatment from the post-treatment assessment. While this approach seems logical, a momentous confounding factor may exist. If through any number of mechanisms and internal processes, a patients' understanding or perception of the construct under evaluation changes over time then comparison of two longitudinal assessments may be analogous to comparison of the proverbial apple and orange. This change in perception has been given the term 'response shift'[6-9]. If response shift occurs between assessments it is entirely likely, that patients will disagree with the magnitude and possibly the direction of conventional change score calculations $[6,8,9]$. The scenario presented below (Scenario 1) illustrates a change in perception that a patient may have experienced when reporting their health-related quality of life using a simple zero to ten scale.

\section{Scenario 1 - A patient visits his doctor six months after undergoing a prostate resection}

Dr: "Tell me Bill (patient), how are you? Tell me on a scale from zero to ten where zero is the worst health you can imagine and ten is the best."

Patient: "Well I'm having a lot of trouble so I would give myself five out of ten."

Dr: "Are you better or worse than how you were six months ago?"

Patient: "When I think back about how I was feeling six months ago, I would give myself a nine out of ten because I wasn't this bad."

Dr: "What did you think at the time? Can you remember what you told me six months ago?"

Patient: "I'm not sure, I remember you asking me, I think I said six out of ten but I didn't know then how bad the symptoms could get."

Dr: "Let me check your file. Here, when I asked you six months ago you actually gave yourself a three out of ten. I made notes here about your pain, your difficulty urinating, and how anxious this was making you feel."

Patient: "Oh, yes, now I remember. I had forgotten about how anxious I was before, but the other symptoms are worse now. So, doctor, are you saying I'm better now than I was back then?" Dr: "You tell me?"
Conflicting change scores may be calculated from this patients' report. Conventional change score calculation would compare the patients' current report (5/10) to their previous report (3/10) and infer an improvement of two points. Philosophically, if we use this calculation as the measure of change, we imply that the most appropriate perspective from which to rate a health state is the perspective held at the time of the assessment. However, this does not consider how an individual's perception of the construct under evaluation, in this case health-related quality of life, might have changed between measurement points (i.e. response shift). It is also possible to calculate patient perceived change by comparison of the current report $(5 / 10)$ with their current perception of how they would rate how they were feeling previously $(9 / 10)$ and infers a reduction of four points. If we use this calculation as the measure of change, we imply that the most appropriate perspective from which to rate a health state is the perspective held at one point in time. An advantage of adopting this view is that changing standards of selfassessment over time are eliminated from the calculation of change. Retrospective reporting of a construct such as this from the patient's current perspective has been termed a 'then test.'[10,11] Then tests are the most commonly reported method of assessing patient perceived change in self-reported outcomes such as health-related quality of life and fatigue to indicate whether response shift has occurred[10-12].

While the 'then test' is useful in revealing the patient's current perception of change and is amenable to use in clinical assessments, it is potentially confounded by recall bias[12]. A patient may not be able to accurately recall their health in relation to the evaluation process at a previous assessment and may remember rating their health as being better or worse than they previously did. Again consider Scenario 1. The patient recalled previously rating their health-related quality of life as $6 / 10$, despite actually rating it as $3 / 10$ at the initial assessment as the patient had forgotten how anxious they were feeling at the time. This three point difference due to imperfect recall would bias a patient's currently perceived change. Thus a third approach to calculating change would be to adjust the patient's currently perceived change for their recall bias. For our scenario in Scenario 1, the patient's recall bias was +3 and the patient perceived change was 4 , resulting in a final change score of -1 .

The three potential change scores are represented by the following equations:

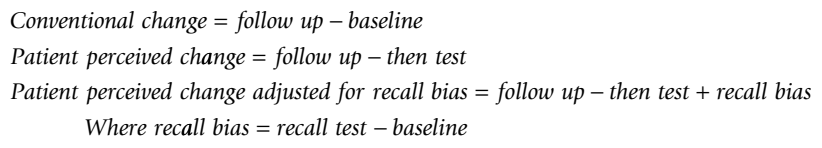


Despite the potentially invalidating consequences of inaccurate representations of change in patient reported outcomes, there have been few empirical investigations providing evidence to inform discussion around this issue. Evidence supporting the existence of response shift amongst various individual patient groups has been reported, $[6,10,13,14]$ although it has been concluded that recall bias may have influenced retrospective assessments of change, such as use of the then-test, to evaluate the magnitude and direction of response shift observed[12,13,15]. Along this line of investigation, a recently study reported poor agreement between conventional change and patient perceived change in healthrelated quality of life amongst a population of older adults[16]. This investigation highlighted the need to take recall bias into account during investigations of patients' perception of change in their health-related quality of life[16]. No investigation has been made to examine the potential impact of response shift and recall bias simultaneously. This study aims to investigate agreement and systematic differences between conventional change and patient perceived change as well as between conventional change and patient perceived change adjusted for recall bias in health-related quality of life amongst a group of older patients accessing healthcare resources.

\section{Methods \\ Design}

Prospective cohort investigation.

\section{Participants and setting}

This investigation included a sample of 103 participants taking part in larger randomised controlled trial at a tertiary hospital in Brisbane, Australia. The larger trial investigated a multi-media patient education program aimed to prevent in-hospital falls amongst hospitalised older adults[17]. The participants in this investigation included a convenience sample of those who were considered by clinical staff to be likely to require a period of subacute in-hospital rehabilitation prior to discharge (with a length of stay greater than two weeks). Patients with moderate to severe cognitive deficits (e.g. MiniMental State Examination[18] $<24 / 30$ or any patient in post-traumatic amnesia) were excluded as were participants with moderate or severe language deficits (e.g. aphasic stroke patients).

This patient group was selected for this investigation for several reasons. First, inpatient rehabilitation amongst hospitalised older adult groups is often focused on improving function to maximise health-related quality of life (rather than a curative effect). Therefore, meaningful evaluation of health-related quality of life is very important amongst this patient group. Additionally, due to the nature of inpatient, multi-faceted and multi disciplinary clinical interventions required, healthcare for this group is resource intensive further heightening the need for accurate and meaningful evaluation of effect. Lastly, due to health events, social changes, peer comparisons and the hospitalisation experience, patients in this group are likely to have experienced adaptation and changes in internal value systems which have lead to a response shift, particularly in regard to reporting their health-related quality of life at the beginning in comparison to the end of their hospitalisation experience.

\section{Measures}

Health-related quality of life was evaluated using the EQ$5 \mathrm{D}$ instrument[19]. The first 5 questions from the EQ-5D investigate the domains of mobility, usual activities, personal care, pain/discomfort and anxiety/depression. For each of these questions the respondent may choose one of three statements indicating they either have no problems, some problems or extreme problems in that domain. A multi-attribute utility score (utility) where death and perfect health are represented by 0 and 1 respectively was calculated from these five questions by applying the Dolan tariff system[20]. Scores less than 0 are considered worse than death and 1 is the maximum score possible. The sixth and final question is an overall health state visual analogue scale (VAS) where worst imaginable and best imaginable health are represented by 0 and 100 respectively[19]. Both the utility and VAS scores were used in this investigation.

For the purpose of calculating conventional change in health-related quality of life over the length of admission, patients completed the EQ-5D on two occasions; after admission (baseline) and immediately prior to discharge (discharge). The difference between these two scores was considered conventional change in health-related quality of life.

For the purpose of calculating patient perceived change in health-related quality of life a 'then test' was also implemented using the EQ-5D instrument at the assessment immediately prior to discharge. This involved the patient reporting how they believe their HRQoL was at the baseline assessment using the EQ-5D instrument. At the discharge assessment after completing the standard EQ-5D, patients were asked to report (from their current perspective) how they believed their health-related quality of life was at the baseline assessment (using the EQ-5D instrument).

For the purpose of calculating patient recall bias, a recall test was also completed at the discharge assessment. When completing the recall test, the patient was asked to indicate what they believed they actually reported on the EQ-5D instrument at the baseline assessment. Patients were asked to complete the recall test after completing the standard EQ-5D and the EQ-5D then test. 
This was the third and final time the EQ-5D instrument was used at the discharge assessment (standard EQ-5D, EQ-5D then test and EQ-5D recall test).

\section{Procedure}

All participants completed a baseline assessment that included the standard EQ-5D as soon as they were deemed medically stable by clinical staff and were able to provide written informed consent (within 72 hours of admission). Participants then completed the standard EQ-5D, EQ-5D then test and EQ-5D recall test at their discharge assessment immediately prior to discharge from the hospital. Length of stay in hospital and hence length of time between assessments was different for each patient. However, 'then test' and 'recall tests' were completed at the discharge assessment with the reference point always being their initial baseline assessment. Participants provided written informed consent prior to participation. Ethical approvals were granted by the Princess Alexandra Hospital Human Research Ethics Committee and The University of Queensland Medical Research Ethics Committee.

\section{Data Analysis}

Demographic information including mean age, baseline and discharge health-related quality of life reports were tabulated (Table 1). Change scores were calculated for both EQ-5D utility and VAS. Conventional change scores were calculated by subtracting the baseline assessment from the discharge assessment. Patient perceived change scores were calculated by subtracting 'then test' scores from the baseline assessment. Patient perceived change adjusted for recall bias was calculated by first calculating the recall bias, then adjusting the patient perceived change by the recall bias amount. To calculate recall bias the baseline assessment was subtracted from the recall test score.

Agreement between conventional change and patient perceived change as well between conventional change and patient perceived change adjusted for recall bias were calculated using intraclass-correlation coefficients and limits of agreement (separately for utility and VAS). To evaluate whether any systematic difference existed (i.e. whether conventional change was consistently higher or lower than patient perceived change or patient perceived change adjusted for recall bias), paired t-tests were employed (Table 2). Bland-Altman plots with limits of agreement [21] were also prepared (Figure 1) to visually represent agreement levels between conventional change and patient perceived change as well as for conventional change and patient perceived change adjusted for recall bias (for EQ-5D utility and VAS).

To examine the magnitude of discrepancy between change scores within individuals, the absolute difference
Table 1: Demographic information for participants included in analysis.

\begin{tabular}{|c|c|}
\hline & $\begin{array}{l}\text { Hospitalised older adults } \\
\qquad(n=103)\end{array}$ \\
\hline $\begin{array}{l}\text { Datasets complete and } \\
\text { included in analysis (\% of } \\
\text { total) }\end{array}$ & $101(98.1 \%)$ \\
\hline $\begin{array}{l}\text { Length of stay in days - } \\
\text { median (IQR) }\end{array}$ & $38(20-60)$ \\
\hline Age - mean (sd) & $73.3(11.2)$ \\
\hline $\begin{array}{l}\text { Female - number (\% of those } \\
\text { patients included in analysis) }\end{array}$ & 48 (47.5\%) \\
\hline $\begin{array}{l}\text { Baseline health-related } \\
\text { quality of life (EQ-5D utility) - } \\
\text { mean (sd) }\end{array}$ & $0.368(0.338)$ \\
\hline $\begin{array}{l}\text { Baseline health-related } \\
\text { quality of life (EQ-5D VAS) - } \\
\text { mean (sd) }\end{array}$ & $63.2(17.1)$ \\
\hline $\begin{array}{l}\text { Perception of baseline at } \\
\text { discharge (EQ-5D utility then } \\
\text { test) - mean (sd)* }\end{array}$ & $0.215(0.406)$ \\
\hline $\begin{array}{l}\text { Perception of baseline at } \\
\text { discharge (EQ-5D VAS then } \\
\text { test) - mean (sd)* }\end{array}$ & $45.7(21.0)$ \\
\hline $\begin{array}{l}\text { Recall of baseline response } \\
\text { (EQ-5D utility recall test) - } \\
\text { mean (sd)* }\end{array}$ & $0.231(0.405)$ \\
\hline $\begin{array}{l}\text { Recall of baseline response } \\
\text { (EQ-5D VAS recall test) - } \\
\text { mean (sd)* }\end{array}$ & $47.5(20.3)$ \\
\hline $\begin{array}{l}\text { Discharge health-related } \\
\text { quality of life (EQ-5D utility) - } \\
\text { mean (sd)* }\end{array}$ & $0.656(0.240)$ \\
\hline $\begin{array}{l}\text { Discharge health-related } \\
\text { quality of life (EQ-5D VAS) - } \\
\text { mean (sd)* }\end{array}$ & 72.5 (16.7) \\
\hline
\end{tabular}

between conventional change and patient perceived change was calculated for each participant (regardless of direction). To assist interpretation of whether the magnitude of difference between these change scores within individuals was clinically meaningful, the number of participants with a discrepancy between utility change scores greater than a minimal clinically important difference of 0.081 was calculated (Table 3$)$. This value (0.081) was previously reported as the median value for EQ-5D utility minimal clinically important difference from a review of 8 investigations incorporating 11 populations[22]. In the same way the absolute difference between conventional change and patient perceived change adjusted for recall bias was also calculated for 
Table 2: Mean change, intraclass correlation coefficient (ICC), and limits of agreement (LOA) between change scores calculated from conventional longitudinal assessments and the patients' perspective (with and without adjustment for recall bias).

\begin{tabular}{|c|c|c|c|c|c|c|c|c|}
\hline \multirow[t]{2}{*}{ Measure } & \multirow{2}{*}{$\begin{array}{c}\text { Patient } \\
\text { perspective } \\
\text { adjusted for } \\
\text { recall bias }\end{array}$} & \multirow{2}{*}{$\begin{array}{l}\text { Conventional } \\
\text { change } \\
\text { mean }(95 \% \\
\text { Cl) }\end{array}$} & \multirow{2}{*}{$\begin{array}{c}\text { Patient } \\
\text { perspective } \\
\text { change } \\
\text { mean }(95 \% \mathrm{Cl})\end{array}$} & \multirow{2}{*}{$\begin{array}{c}\text { ICC } \\
(95 \% \mathrm{Cl})\end{array}$} & \multicolumn{3}{|c|}{ Limits of agreement } & \multirow[t]{2}{*}{ p-value* } \\
\hline & & & & & $\begin{array}{c}\text { Lower LOA } \\
(95 \% \mathrm{Cl})\end{array}$ & $\begin{array}{c}\text { Mean } \\
\text { difference } \\
(95 \% \mathrm{Cl})\end{array}$ & $\begin{array}{c}\text { Upper LOA } \\
(95 \% \mathrm{Cl})\end{array}$ & \\
\hline EQ-5D Utility & No & $\begin{array}{c}0.287 \\
(0.216,0.359)\end{array}$ & $\begin{array}{c}0.441 \\
(0.367,0.518)\end{array}$ & $\begin{array}{c}0.34 \\
(0.16,0.50)\end{array}$ & $\begin{array}{c}-1.007 \\
(-1.092,-0.922)\end{array}$ & $\begin{array}{c}-0.150 \\
(-0.239,-0.069)\end{array}$ & $\begin{array}{c}0.700 \\
(0.616,0.785)\end{array}$ & $<0.001^{*}$ \\
\hline EQ-5D Utility & Yes & $\begin{array}{c}0.287 \\
(0.216,0.359)\end{array}$ & $\begin{array}{c}0.303 \\
(0.232,0.375)\end{array}$ & $\begin{array}{c}0.98 \\
(0.97,0.99)\end{array}$ & $\begin{array}{c}-0.150 \\
(-0.163,-0.136)\end{array}$ & $\begin{array}{c}-0.016 \\
(-0.116,-0.084)\end{array}$ & $\begin{array}{c}0.118 \\
(0.105,0.131)\end{array}$ & $0.019^{*}$ \\
\hline EQ-5D VAS & No & $\begin{array}{c}9.3 \\
(5.4,13.2)\end{array}$ & $\begin{array}{c}26.7 \\
(22.8,30.7)\end{array}$ & $\begin{array}{c}0.40 \\
(0.22,0.55)\end{array}$ & $\begin{array}{c}-60.7 \\
(-65.0,-56.4)\end{array}$ & $\begin{array}{c}-17.4 \\
(-21.7,-13.1)\end{array}$ & $\begin{array}{c}25.8 \\
(21.5,30.1)\end{array}$ & $<0.001^{*}$ \\
\hline EQ-5D VAS & Yes & $\begin{array}{c}9.3 \\
(5.4,13.2)\end{array}$ & $\begin{array}{c}11.0 \\
(6.7,15.3)\end{array}$ & $\begin{array}{c}0.90 \\
(0.86,0.93)\end{array}$ & $\begin{array}{c}-19.9 \\
(-21.8,-18.1)\end{array}$ & $\begin{array}{c}-1.7 \\
(-3.5,0.1)\end{array}$ & $\begin{array}{c}16.5 \\
(14.7,18.3)\end{array}$ & 0.060 \\
\hline
\end{tabular}

* A p-value $<0.05$ indicates that a systematic difference exists (i.e. change from patient perspective was either consistently higher or consistently lower than conventional change scores.

each participant, and the number with a discrepancy in utility greater than 0.081 was also calculated (Table 3).

To specifically investigate the effect of recall bias on patient perceived change, agreement between patient perceived change with and without adjustment for recall bias was also calculated using intraclass-correlation coefficients and limits of agreement (Table 4). To evaluate whether any systematic difference existed (i.e. whether adjusting for recall bias resulted in consistently higher or lower patient perceived change scores), paired t-tests were employed (Table 4).

\section{Results}

Demographic and health-related quality of life reports are presented in Table 1. Two datasets were incomplete due to the unexpected discharge of two patients from hospital (without reassessment); these two datasets were excluded from all analysis. From the baseline assessment it can be seen that health-related quality of life was low amongst this elderly, hospitalised patient group[23]. The median (inter-quartile range) for length of stay was 38 (20-60) days.

Mean change scores and agreement statistics between conventional change and patient perceived change as well as between conventional change and patient perceived change adjusted for recall bias are presented in Table 2 . Intraclass correlation coefficient (ICC) statistics indicated that agreement between conventional change and patient perceived change was not strong $(\mathrm{EQ}-5 \mathrm{D}$ utility $=$ 0.34 , EQ-5D VAS $=0.40$ ). This was consistent with the limits of agreement statistics and Bland-Altman plots (Figure 1a and 1c) which covered a large proportion of the possible change scores. After adjusting patient perceived change for recall bias, ICC statistics (EQ-5D utility $=0.98, \mathrm{EQ}-5 \mathrm{D}$ VAS $=0.90)$, limits of agreement and Bland-Altman plots (Figure 1b and 1d) indicated that agreement with conventional change was much stronger. The mean patient perceived change was greater than mean conventional change scores for both utility and VAS. Although this mean difference was statistically significant with and without adjustment for recall bias, the magnitude of the mean difference only exceeded reported minimal values for clinically important difference when no adjustment for recall bias was made (Table 2)[22]

The absolute difference between conventional change scores and patient perceived change score (with and without adjustment for recall bias) are presented in Table 3. Within individuals, discrepancy between conventional longitudinal change and patient perceived change was considered clinically meaningful for 84 (83.2\%) of participants, after adjusting for recall bias this reduced to 8 (7.9\%).

Agreement between patient perceived change scores with and without adjustment for recall bias was not strong. Agreement statistics for this relationship are presented in Table 4. Intraclass correlation coefficients did not indicate strong agreement for either EQ-5D utility $(\mathrm{ICC}=0.36)$ or EQ-5D VAS $(\mathrm{ICC}=0.50)$. This was consistent with the limits of agreement, which covered a large proportion of possible responses (Table 4). Mean 


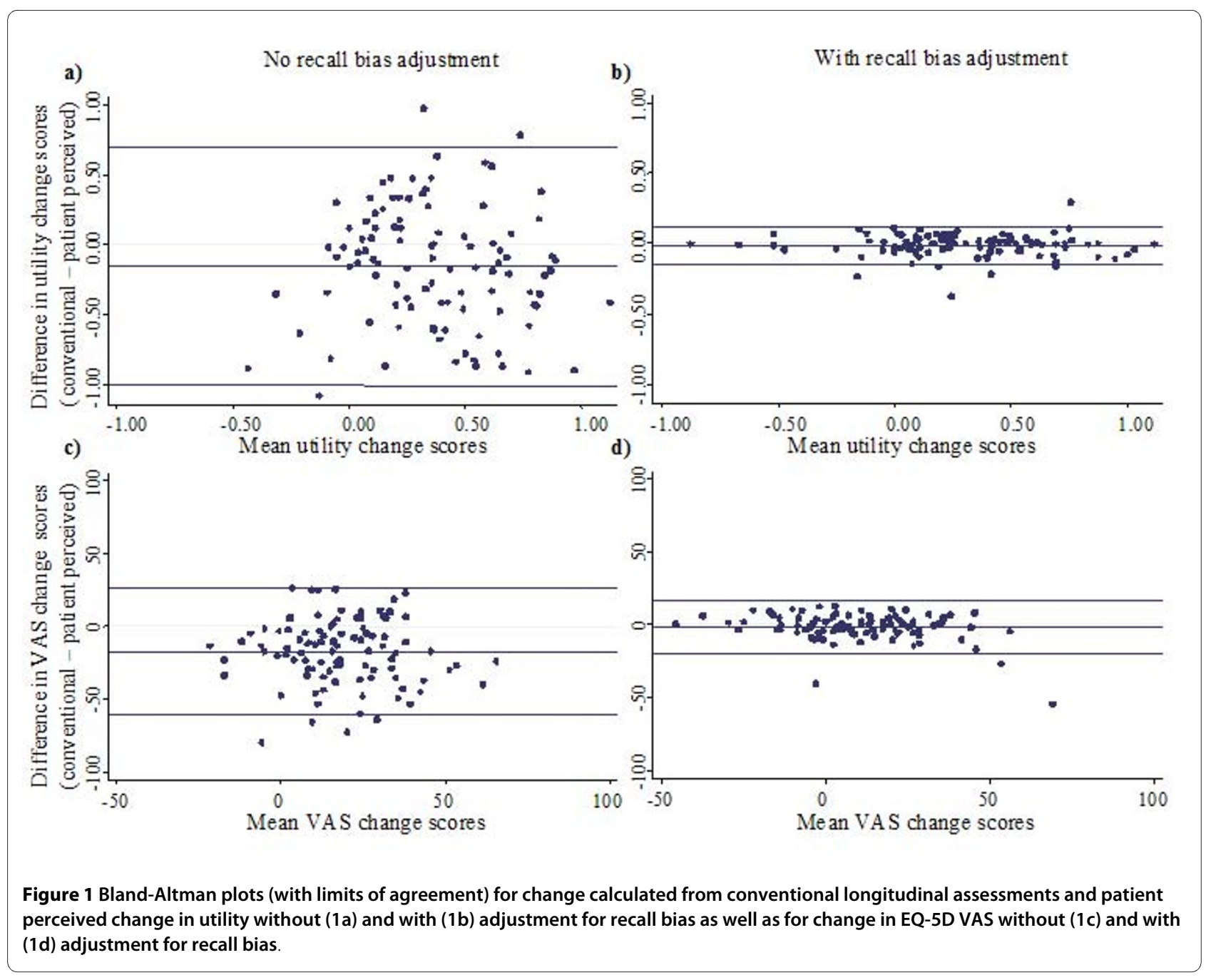

patient perceived change in EQ-5D utility and VAS was less positive after adjustment for recall bias $(\mathrm{p}=0.002$ and $\mathrm{p}<0.001$ respectively) with the size of this difference large enough to be considered clinically meaningful (Table 4)[22].

\section{Discussion}

\section{Main findings}

Serious undesirable consequences may result from inaccurate representation of change in self-reported patient health states. This investigation has indicated that agree- ment between conventional change and patient perceived change in health-related quality of life, as evaluated with the 'then test,' was not strong (agreement coefficient levels below 0.40 are considered indicative of poor agreement)[24-26]. Additionally, mean conventional change scores were significantly lower than patient perceived change scores (Table 2 and Figure 1), this difference was large enough to be considered clinically meaningful[22]. Within individuals the disagreement between conventional longitudinal change and patient perceived change was substantial with $83.2 \%$ of individuals reporting a dis-

Table 3: Absolute differences between conventional and patient perceived change (with and without adjustment for recall bias) and the number of patients with this difference greater than a minimal clinically important difference (MCID) in utility of 0.081 .

\begin{tabular}{ccc}
\hline & $\begin{array}{c}\text { Utility } \\
\text { mean }(\mathbf{s d})\end{array}$ & $\begin{array}{c}\text { VAS MCID } \\
\text { mean (sd) } \\
\text { number (\%) }\end{array}$ \\
\hline No adjustment for recall bias & $0.363(0.273)$ & $22.3(16.6)$ \\
With adjustment for recall bias & $0.021(0.066)$ & $3.5(8.6)$ \\
\hline
\end{tabular}


Table 4: Mean change, intraclass correlation coefficient (ICC), and limits of agreement (LOA) between change scores calculated from the patients' perspective with adjustment for recall bias and from the patients' perspective without adjustment for recall bias.

\begin{tabular}{|c|c|c|c|c|c|c|c|}
\hline \multirow[t]{2}{*}{ Measure } & \multicolumn{2}{|c|}{ Patient perspective of change } & \multirow{2}{*}{$\begin{array}{c}\text { ICC } \\
(95 \% \mathrm{CI})\end{array}$} & \multicolumn{3}{|c|}{ Limits of agreement } & \multirow[t]{2}{*}{ p-value* } \\
\hline & $\begin{array}{l}\text { With recall bias } \\
\text { adjustment } \\
\text { mean }(95 \% \mathrm{Cl})\end{array}$ & $\begin{array}{l}\text { Without recall } \\
\text { bias adjustment } \\
\text { mean }(95 \% \mathrm{CI})\end{array}$ & & $\begin{array}{l}\text { Lower LOA } \\
(95 \% \mathrm{Cl})\end{array}$ & $\begin{array}{c}\text { Mean difference } \\
(95 \% \mathrm{CI})\end{array}$ & $\begin{array}{c}\text { Upper LOA } \\
(95 \% \mathrm{Cl})\end{array}$ & \\
\hline EQ-5D Utility & $\begin{array}{c}0.303 \\
(0.232,0.375)\end{array}$ & $\begin{array}{c}0.441 \\
(0.367,0.518)\end{array}$ & $\begin{array}{c}0.36 \\
(0.18,0.52)\end{array}$ & $\begin{array}{c}-0.979 \\
(-1.063,-0.895)\end{array}$ & $\begin{array}{c}-0.138 \\
(-0.221,-0.054)\end{array}$ & $\begin{array}{c}0.704 \\
(0.620,0.787)\end{array}$ & $0.002^{*}$ \\
\hline EQ-5D VAS & $\begin{array}{c}11.0 \\
(6.7,15.3)\end{array}$ & $\begin{array}{c}26.7 \\
(22.8,30.7)\end{array}$ & $\begin{array}{c}0.50 \\
(0.34,0.64)\end{array}$ & $\begin{array}{c}-57.1 \\
(-61.2,-53.0)\end{array}$ & $\begin{array}{c}-15.7 \\
(-19.8,-11.6)\end{array}$ & $\begin{array}{c}25.7 \\
(21.6,29.8)\end{array}$ & $<0.001^{*}$ \\
\hline
\end{tabular}

*A p-value $<0.05$ indicates that a systematic difference exists (i.e. patient perspective of change adjusted for recall bias was consistently higher or consistently lower than when no adjustment for recall bias was made.

crepancy great enough to be considered clinically meaningful (Table 3).

After adjusting patient perceived change for recall bias the agreement with conventional change was much stronger (Table 2 and Figure 1). The mean difference also diminished to a level below that which is likely to be considered clinically meaningful difference[22]. Furthermore after adjustment for recall bias, agreement between patient perceived change and conventional change was much stronger within individuals, with only $7.9 \%$ reporting a discrepancy large enough to be considered clinically meaningful (Table 3). Adjusting patient perceived change for recall bias resulted in less positive reports of change in both EQ-5D utility and VAS (Table 4).

The pattern of main findings described above indicate that amongst this patient sample over the duration of their hospital stay, a large proportion of the disagreement between patient perceived change and conventional longitudinal change could be attributed to recall bias rather than response shift. While this was the case during the investigation at hand, the relative contribution of response shift and recall bias may vary across other patient groups and amongst this type of population in other circumstances (such as the transition from hospital to the community). Response shift has the potential to invalidate conventional change scores while recall bias has the potential to invalidate patient perceived change measured using retrospective reports, such as the thentest. This investigation has been the first to incorporate a method of adjusting patient perceived change for patient recall bias.

\section{Wider implications}

For an individual patient, inappropriate implementation, continuation or cessation of a health intervention may occur if a decision is reached based on clinical reasoning flawed by inaccurate representations of change in a relevant self-reported outcome. Perhaps of even greater consequence, evaluation of the effectiveness of a certain health intervention during a randomised trial may be compromised if one group experiences a systematic response shift[27]. In this investigation the mean conventional change was statistically lower and than the mean patient perceived change (even after adjustment for recall bias) implying that a systematic response shift (albeit very small in this case) had occurred. If during a randomised trial, a systematic response shift of a clinically important magnitude occurred due to the nature of an intervention, inappropriate conclusions regarding effect on healthrelated quality of life may be drawn. Furthermore other clinically important patient reported outcomes such as pain, fatigue and anxiety, may be affected.

Consider a trial examining a certain experimental surgery designed to reduce rheumatic pain in comparison to conventional conservative management. It is possible that patients in the surgery group may experience a very painful and prolonged post-operative recovery period, which could result in a response shift in relation to their pain rating. If this were to occur, conventional post - pre evaluation of pain ratings may imply a reduction in pain despite individuals not actually feeling any less pain then they did prior to the surgery. A false positive result such as this is likely to lead to further investigations of the technique that may also report similar results and ultimately superfluous adoption of a potentially harmful intervention[27]. Economic evaluation of health interventions may also be invalidated if a similar effect resulted in an inaccurate representation of change in health-related quality of life that was subsequently used in a cost-utility analysis.

The method of adjustment reported in this investigation has the potential to highlight invalidating effects of 
response shift and recall bias as well as offering an alternate method for change score calculation. A response shift and recall bias sensitivity analysis could be conducted to examine whether the different methods of change score calculation affects conclusions drawn in clinical trials. If the same conclusions would be drawn regardless of whether conventional or adjusted change scores were used, this may indicate that results were robust against response shift and recall bias. However, further investigation and discussion regarding this proposed adjustment technique is warranted before adoption into wider use.

\section{Comparison to previous research}

This investigation has employed a novel approach allowing for adjustment to self-reported outcomes to be made using a retrospective report (then test) adjusted for recall bias which may be replicated in both clinical and research settings in an effort to reduce the invalidating effects of response shift and recall bias. Comparison to prior research is difficult as this is the first investigation to employ an adjustment for patient recall bias when utilising a then-test approach. However, empirical evidence from this investigation is in line with conceptual models surrounding the response shift phenomenon[7,8]. Results from the then test without adjustment for recall bias reported in this investigation are also congruent with previous investigations of response shift that have not adjusted for recall bias $[10,11,13,17]$. The results from this investigation suggest that recall bias is likely to affect retrospective reports amongst patient groups similar to those in this sample and this should be taken into account in future investigations utilising retrospective reporting techniques such as the then test approach.

\section{Limitations and future directions}

Direct extrapolation of these results may be limited to patient populations similar to those included in this study. Other patient groups and older adults in differing circumstances may not have responded in the same way as participants in this investigation. Furthermore, healthrelated quality of life was the only construct under investigation in this study and only one generic instrument (EQ-5D) was used to evaluate this construct. However, a method of adjusting patient perceived change for recall bias has been described in this investigation that may be applied amongst other population groups and clinical settings. Further empirical research along this line of investigation is warranted, as is further discussion regarding the best way for clinicians and researchers alike to discern 'real change' amongst patient reported outcomes of a subjective nature. Particularly amongst patient groups where improvement in these subjective constructs is often the ultimate aim of health interventions rather than a straightforward curative effect on a known pathology.

Another important area for future investigation and discussion is in regard to which perspective of change is the most important to various stakeholders (meaningful change as perceived by patients, their family/carers, health experts or organisations, other members of society who fund health interventions through taxes and insurance premiums etc.). Future investigation and discussion of these issues are required to maximise health outcomes for all members of society.

\section{Conclusions}

Agreement between conventional change and patient perceived change was not strong. A large proportion of this disagreement may be attributable to recall bias. To overcome the invalidating effect of response shift (on conventional change) and recall bias (on patient perceived change) a method of adjusting patient perceived change for recall bias has been described.

\section{Acknowledgements}

Terry Haines is supported by a National Health and Medical Research Council (Australia) Career Development Award (606732).

This project was supported by a National Health and Medical Research Council (Australia) Project Grant (456097).

\section{Competing interests}

The authors declare that they have no competing interests.

\section{Authors' contributions}

SM contributed to research idea conception, planning of research processes, data analysis and manuscript preparation, as well as manuscript review, appraisal and editing. TH contributed to research idea conception, planning of research processes as well as manuscript review, appraisal and editing. Both authors read and approved the final manuscript.

\section{Author Details}

${ }^{1}$ Centre for Functioning, Disability and Health Research, Queensland Health Buranda Plaza, Corner of Ipswich Road and Cornwall Street, Brisbane, Australia, 2School of Public Health and Institute of Health and Biomedical Innovation, Queensland University of Technology, Kelvin Grove, Australia, ${ }^{3}$ The University of Queensland, School of Health and Rehabilitation Sciences, St Lucia, Australia , 4 Southern Health, Allied Health Clinical Research Unit, Kingston Centre, Cnr Warrigal and Kingston Roads, Cheltenham, Australia and 5 Monash University, Physiotherapy Department, School of Primary Health Care, Monash University Peninsular Campus, Victoria, Australia

Received: 8 April 2010 Accepted: 10 July 2010

Published: 10 July 2010

\section{References}

1. Crosby RD, Kolotkin RL, Williams GR: Defining clinically meaningful change in health-related quality of life. J Clin Epidemio/ 2003, 56(5):395-407

2. Sullivan M: The new subjective medicine: taking the patient's point of view on health care and health. Soc Sci Med 2003, 56(7):1595-1604

3. Wiklund I: Assessment of patient-reported outcomes in clinical trials: the example of health-related quality of life. Fundam Clin Pharmacol 2004, 18(3):351-363. 
4. Drummond MF, Iglesias CP, Cooper NJ: Systematic reviews and economic evaluations conducted for the National Institute for Health and Clinical Excellence in the United Kingdom: a game of two halves? Int J Technol Assess Health Care 2008, 24(2):146-150.

5. Bullinger M: Assessing health related quality of life in medicine. An overview over concepts, methods and applications in international research. Restor Neurol Neurosci 2002, 20(3-4):93-101.

6. Schwartz CE, Andresen EM, Nosek MA, Krahn GL: Response shift theory: important implications for measuring quality of life in people with disability. Arch Phys Med Rehabil 2007, 88(4):529-536.

7. Schwartz CE, Rapkin BD: Reconsidering the psychometrics of quality of life assessment in light of response shift and appraisal. Health Qual Life Outcomes 2004, 2:16.

8. Sprangers M, Schwartz C: Integrating response shift into health-related quality of life research: a theoretical model. Social Science and Medicine 1999, 48(11):1507-1515.

9. Visser MR, Smets EM, Sprangers MA, de Haes HJ: How response shift may affect the measurement of change in fatigue. J Pain Symptom Manage 2000, 20(1):12-18

10. Sprangers MA, Van Dam FS, Broersen J, Lodder L, Wever L, Visser MR, Oosterveld P, Smets EM: Revealing response shift in longitudinal research on fatigue--the use of the thentest approach. Acta Oncol 1999, 38(6):709-718.

11. Visser MR, Oort FJ, Sprangers MA: Methods to detect response shift in quality of life data: a convergent validity study. Qual Life Res 2005 14(3):629-639.

12. Schwartz C, Sprangers M: Methodological approaches for assessing response shift in longitudinal health-related quality-of-life research. Social Science and Medicine 1999, 48:1531-1548.

13. Ahmed S, Mayo NE, Wood-Dauphinee S, Hanley JA, Cohen SR: The structural equation modeling technique did not show a response shift, contrary to the results of the then test and the individualized approaches. J Clin Epidemio/ 2005, 58(11):1125-1133.

14. Oort FJ, Visser MR, Sprangers MA: An application of structural equation modeling to detect response shifts and true change in quality of life data from cancer patients undergoing invasive surgery. Qual Life Res 2005, 14(3):599-609.

15. Ahmed S, Mayo NE, Wood-Dauphinee S, Hanley JA, Cohen SR: Response shift influenced estimates of change in health-related quality of life poststroke. J Clin Epidemiol 2004, 57(6):561-570.

16. McPhail S, Comans T, Haines T: Evidence of disagreement between patient perceived change and conventional longitudinal evaluation of change in health-related quality of life amongst older adults. Clin Rehabil 2010 in press.

17. Hill AM, Hill K, Brauer S, Oliver D, Hoffmann T, Beer C, McPhail S, Haines TP: Evaluation of the effect of patient education on rates of falls in older hospital patients: description of a randomised controlled trial. BMC Geriatr 2009, 9:14.

18. Folstein MF, Folstein SE, McHugh PR: "Mini-mental state". A practical method for grading the cognitive state of patients for the clinician. J Psychiatr Res 1975, 12(3):189-198.

19. Rabin R, de Charro F: EQ-5D: a measure of health status from the EuroQol Group. Ann Med 2001, 33(5):337-343.

20. Dolan P, Roberts J: Modelling valuations for Eq-5d health states: an alternative model using differences in valuations. Med Care 2002, 40(5):442-446.

21. Bland JM, Altman DG: Statistical methods for assessing agreement between two methods of clinical measurement. Lancet 1986, 1(8476):307-310.

22. Walters SJ, Brazier JE: Comparison of the minimally important difference for two health state utility measures: EQ-5D and SF-6D. Qual Life Res 2005, 14(6):1523-1532.

23. Kind P, Dolan P, Gudex C, Williams A: Variations in population health status: results from a United Kingdom national questionnaire survey. BMJ (Clinical research ed) 1998, 316(7133):736-741.

24. Shrout PE, Fleiss JL: Intraclass correlations: uses in assessing rater reliability. Psychological bulletin 1979, 86(2):420-428.

25. Cicchetti DV, Sparrow SA: Developing criteria for establishing interrater reliability of specific items: applications to assessment of adaptive behavior. American journal of mental deficiency 1981, 86(2):127-137.

26. Pickard AS, Johnson JA, Feeny DH, Shuaib A, Carriere KC, Nasser AM: Agreement between patient and proxy assessments of health-related quality of life after stroke using the EQ-5D and Health Utilities Index. Stroke 2004, 35(2):607-612.

27. McPhail S, Haines T: The Response Shift Phenomenon in Clinical Trials. Journal of Clinical Research Best Practices 2009, 5(12):

doi: 10.1186/1477-7525-8-65

Cite this article as: McPhail and Haines, Response shift, recall bias and their effect on measuring change in health-related quality of life amongst older hospital patients Health and Quality of Life Outcomes 2010, 8:65

\section{Submit your next manuscript to BioMed Centra and take full advantage of:}

- Convenient online submission

- Thorough peer review

- No space constraints or color figure charges

- Immediate publication on acceptance

- Inclusion in PubMed, CAS, Scopus and Google Scholar

- Research which is freely available for redistribution

Submit your manuscript at www.biomedcentral.com/submit
C) BioMed Central 